\title{
Advancements in diagnosis and treatment of meningeal carcinomatosis in solid cancer
}

\author{
Jun-Zhao Cui, Jun-Ying He, Qing Li, Xiao-Qing Li, Rui-Ping Gao, Hui Bu, Yue-Li Zou, Xiao-Su Guo, \\ Wei-Xin Han, Ze-Yan Zhao, Yuan-Yuan Li, Ming-Ming Zheng, Ya-Juan Liu, Li-Tian Yan \\ Department of Neurology, The Second Hospital of Hebei Medical University, Shijiazhuang 050000, Hebei, China.
}

Correspondence to: Prof. Jun-Ying He, Department of Neurology, The Second Hospital of Hebei Medical University, 215 Heping West Road, Shijiazhuang 050000, Hebei, China. E-mail: hjy_zn@126.com

How to cite this article: Cui JZ, He JY, Li Q, Li XQ, Gao RP, Bu H, Zou YL, Guo XS, Han WX, Zhao ZY, Li YY, Zheng MM, Liu YJ, Yan LT. Advancements in diagnosis and treatment of meningeal carcinomatosis in solid cancer. Neuroimmunol Neuroinflammation 2017;4:167-78.

Prof. Jun-Ying He is a director of Neurology at the Second Affiliated Hospital of Hebei Medical University, a chief
physician, and a postgraduate tutor. She also serves as deputy team leader for Infection and Cerebrospinal
Fluid Study Group in Neurology Branch of Chinese Medical Association. She has a deeper study on infectious
disease of central nervous system. The cytomorphology examination in cerebrospinal fluid she developed for the
diagnoses of meningeal carcinomatosis, achieves the domestic leading level. She has undertaken a number of
national and provincial research projects for the past years. She serves as editorial board member of Chinese
Journal of Brain and Neurological Diseases.

Article history:

Received: 16 May 2017

Accepted: 6 Jul 2017

Published: 18 Sep 2017

Key words:

Meningeal carcinomatosis,

diagnosis,

treatment

\section{ABSTRACT}

\section{INTRODUCTION}

Meningeal carcinomatosis (MC), also called neoplastic meningitis is a disease in which intracranial primary tumors or extracranial malignant tumors diffuse, disseminate or focally invade into the meninges and spinal subarachnoid. ${ }^{[1-4]}$ In 1870, Swiss pathologist Eberth $^{[5]}$ demonstrated the selective infiltration of carcinoma cells in the leptomeninges in an autopsy case with lung cancer, while pathological anatomy revealed no inflammation in meninges. The term MC was proposed first to describe the clinical condition 
by Siefert in 1902. This disease was uncommon at that time, and usually confirmed by autopsies. In the past few decades, $10-30 \%$ of people with solid tumors progress to nervous system metastasis, with $4-15 \%$ developing into MC. ${ }^{[6,7]}$ The metastases most frequently come from carcinoma of the breast, lung, gastrointestinal tract, and melanoma. Adenocarcinoma is the most common histologic types. ${ }^{[8]}$ This disorder is easy to be misdiagnosed because of the diverse clinical manifestations and lack of specificity.

This article systematically reviewed the epidemiology, pathogenesis, clinical manifestation, auxiliary examination, diagnosis, treatment and prognostic aspects.

\section{EPIDEMIOLOGY}

With the development of imaging technique and therapies, the survival time of patients with $M C$ is prolonged and the incidence of $\mathrm{MC}$ is growing. MC can occur secondary to tumors have not been discovered and in antitumor therapy, which was most common in older individuals. About $4-7 \%$ of patients with solid tumor suffer meningeal metastasis,,$^{[9-11]}$ with lung cancer $(9-25 \%)$, gastrointestinal tumor $(4-14 \%)$, breast cancer $(2-5 \%)$ and malignant melanoma $(23 \%)$ as the most common causes. MC can be also detected clinically in $5-15 \%$ of patients with hematological malignancies (lymphomatosis or lymphomatous) and primary brain tumors (gliomatosis). ${ }^{[12]}$ However, there are still cancers with an unknown primary (1-7\%). Above all, MC is a relatively late event in carcinoma process.

\section{PATHOPHYSIOLOGY}

In many $\mathrm{MC}$ cases, the damages can be seen in autopsies as brain tissue edema, enlarged cerebral gyrus, meningeal congestion, cerebrospinal membrane greyish white in color, ventriculomegaly on sectioning. Microscopically, tumor cells can be seen in the cerebrospinal membrane and subarachnoid space diffusely or focally, while nodules are not obtained in cerebral parenchyma.

Cancer cells may leave the primary tumor to meningeal by following routes: malignant neoplasms cells may shift to subarachnoid space or cerebral ventricles by hematological invasion, with later spread to the cerebrospinal fluid (CSF). Both the perineural or perivascular spaces and cranial or radicular nerve pathway carry tumor cells to dura mater, leptomeninges, or the ependyma, leading to tumor deposits. Neoplastic cells may spread to the meninges directly.

\section{DIAGNOSIS}

The diagnosis of MC may be confirmed on the basis of the National Comprehensive Cancer Network guidelines ${ }^{[13]}$ The guidelines indicated that any one of the criteria listed below are sufficient to diagnose MC; positive CSF cytology; neuroimaging findings consistent with $\mathrm{MC}$, supportive clinical signs and symptoms and a nonspecific but abnormal CSF changes (increased white blood cell count, decreased glucose, and high protein concentration) in patients suffering from tumor. Despite substantial false negative rate, CSF cytology remains the gold diagnostic standard. In addition to the cytological/neuroimaging/ clinical diagnosis, other CSF parameters such as $\beta$-glucuronidase, creatine-kinase BB isoenzyme (CK$\mathrm{BB}$ ), etc. may be regarded as adjuvant diagnosing for $M C$ and are also used to monitor the treatment response. Furthermore, the diagnostic value of the tumor-derived cell-free DNA in the CSF is promising and may improve the diagnostic yield of CSF analysis.

\section{Clinical characteristics}

Multiple interrelated events result in clinical symptoms of MC, such as obstruction of CSF reflux leading to hydrocephalus, nutrient metabolism competition between neoplastic cells and normal cells resulting in neurological function deficit, tumors invasion of Vichow Robin Spaces. Most patients with MC first presented with headache, nausea, vomiting, epilepsy, cervical radicular pain, hemiplegia and unconsciousness. In a cohort of 60 patients with breast cancer leptomeningeal metastases, headache was the most common presenting symptoms $(55 \%)$, followed by various cranial neuropathies and epilepsy (50\% and $12 \%$, respectively). Vertigo presented in 12 patients (20\%). ${ }^{[14]}$ Classically, MC presents with various clinical signs and symptoms in three domains of neurologic function: the cerebral hemispheres; the cranial nerves; and the spinal cord and associated roots. ${ }^{[15]}$

Headache, nausea, vomiting are the most frequent manifestations of cerebral hemisphere dysfunction. Other signs include hemiplegia, aphasia, changes in mental status, seizures and cognitive impairments. However, simple focal ischemic cerebral injury and non-communicating hydrocephalus are uncommon. Diplopia, hearing impairment, hemianopsia, and trigeminal sensory loss are common symptoms of cranial nerve involvement with the $\mathrm{VI}$ cranial nerve being the most frequently impaired, followed by cranial nerve III and IV. The most frequent spinal 
signs and symptoms include lower motor weakness, dermatomal sensory loss, pain in the neck or back and radiculopathy. Nuchal rigidity is less common which present in less than $15 \%$ of cases. ${ }^{[16,17]}$

\section{CSF examination}

\section{Routine CSF examination}

Intracranial hypertension ( $200 \mathrm{mmH}_{2} \mathrm{O}$ ) is observed in $46 \%$ cases with MC. More than $90 \%$ of patients with MC have abnormal routine test and biochemistry indicators in CSF with increased leukocytes $\left(>4 / \mathrm{mm}^{3}\right)$ in $57 \%$, elevated protein $(>50 \mathrm{mg} / \mathrm{dL})$ in $76 \%$, and decreased glucose $(<60 \mathrm{mg} / \mathrm{dL})$ in $54 \%$. ${ }^{[18]}$ The nonspecific routine CSF examination should not dissuade consideration of this diagnosis.

\section{CSF cytology}

Cytological examination of CSF is still the golden criteria. The literatures reported ${ }^{[19]}$ that the sensibility of May-Grunwald Giemsa stain method for diagnosing MC was $75-90 \%$, with the specificity $100 \%$. Prior related foreign researchers ${ }^{[20]}$ suggest that the positive rate of CSF cytology with the first lumbar puncture is $45 \%$, which increased to $80-90 \%$ with a second CSF exam. Little benefit is obtained from a third lumbar puncture. Of the 42 patients with $\mathrm{MC}$ accepted into the trial reported by $\mathrm{He}$ et al., ${ }^{[21]}$ the sensitivity of a first lumbar puncture is $85.7 \%$, while the tumor cells were found in remaining $14.3 \%$ of cases from repeat lumbar punctures. There are still some false positive rates of CSF cytology check. Sometimes it is hard to distinguish the normal cells from the lymphoma cells.

Some simple measures can improve the sensitivity for the diagnosis including CSF sample disposal. The CSF specimen should be processed within an hour after collection which will improve the sensitivity of CSF cytology. Large CSF sampling volumes (> $10.5 \mathrm{~mL}$ ) is also critical to improve the yield of CSF sensitivity. ${ }^{[22]}$ May-Grünwald-Giemsa staining is better than Papanicolou stain for delineation of nuclear morphological characteristics and cytoplasmic limits. Nonetheless, there remains $25-30 \%$ of patients with MC diagnosed based on clinical picture, and radiographic findings, and persistently negative CSF cytology. ${ }^{[14,18]}$

\section{Tumor markers}

The evaluation of serial biochemical markers in the CSF may be of value in the adjunctive diagnosis of $M C$ and assessment in therapeutic efficacy. Some biomarkers may be nonspecific, such as $\beta$-glucuronidase, CK-BB, lactate dehydrogenase, tissue polypeptide antigen, beta2-microglobulin, carcinoembryonic antigen, vascular endothelial growth factor (VEGF), which can be helpful as indirect indices of MC. ${ }^{[23,24]}$ Other tumor markers such as carbohydrate antigen 15-3, carbohydrate antigen, carbohydrate antigen 125, carbohydrate antigen, neuron specific enolase, alfafetoprotein, CYFRA 21-1, and epidermal growth factor receptor (EGFR) can be relatively specific for MC when increased in CSF compared to serum. ${ }^{[25-27]}$ Combined assay of different markers may enhance the sensitivity of MC diagnosis. ${ }^{[26]}$ Occasionally, the biomarkers provide diagnostic support for $M C$ in cases suspected as MC with negative CSF cytology. ${ }^{[28]}$ However, detection of tumor cells in the CSF by CSF cytology remains the golden criteria for diagnosis of MC.

\section{Genetic testing}

When tumors diffuse into the central nervous system (CNS), the patients are usually already in an advanced disease stage and is unresponsive to therapy. Mechanisms of cancer dissemination and development within the CNS are unknown due to limited access to tumor tissue. Sasaki et al. ${ }^{[29]}$ analyzed the EGFR mutation status of CSF straightly using real-time polymerase chain reaction that was more sensitive than cytology to diagnose $M C$ in seven patients with non-small cell lung carcinoma (NSCLC) harboring an EGFR mutation (sensitivity of $100 \%$ vs. $28.6 \%$ ). A separate study used nextgeneration sequencing by Pentsova et al ${ }^{[30]}$ to reveal somatic alterations in tumor-derived DNA from CSF in patients with CNS metastases of solid tumors and primary brain tumors. These studies demonstrated that identification of genomic mutations in tumorderived cell-free DNA from CSF using a sufficiently sensitive platform in patients with CNS involvement. These techniques may be useful in complementing the diagnosis of $\mathrm{MC}$, monitoring response to therapy and identifying resistance mutations. Therefore, in recent years, CSF has attracted the greatest attention and may be considered as a "liquid biopsy" for patients with MC. Currently, the technology of highthroughput sequencing of CSF may recognize cancerrelated DNA in cases with known or suspected CNS involvement, which will provide significant aid for the diagnosis and treatment response.

\section{Neurological imaging}

Computed tomography (CT) is not sensitive in diagnosing $\mathrm{MC}$ with an estimated $23-38 \%$ of sensitivity of scan reported. ${ }^{[31,32]}$ Magnetic resonance imaging (MRI) is considered the standard for the cancer patients with clinical suggestive of MC. ${ }^{[33]}$ The sensitivity of MRI in the diagnoses of MC varied from $20 \%$ to $91 \% \cdot{ }^{[11,14,34]}$ Subarachnoid or ventricular enhancing nodules, diffuse or focal leptomeningeal enhancement, ependymal, sulcal, and nerve root enhancement are common MRI findings in MC. Brain parenchymal metastases can be observed in $21-82 \%$ of $\mathrm{MC}^{[34-37]}$ 
Any stimulation of the pia mater, such as subarachnoid blood, infection and cancer can produce enhancement of MRI. Lumbar puncture itself can induce a meningeal reaction resulting in leptomeningeal enhancement, so it would be better to conduct MRI examination prior the procedure. ${ }^{[38]}$ Nevertheless, negative findings cannot be excluded the diagnosis of MC absolutely.

Researches on radionuclide using either ${ }^{111}$ Indiumdiethylenetriamine penta-acetic acid or ${ }^{99} \mathrm{Tc}$ macroaggregated albumin are regarded as effective technique of choice to monitor and evaluate CSF flow dynamics. ${ }^{[39,40]}$ CSF flow blocks have been demonstrated in $30-70 \%$ of patients with MC, with blocks usually arises in the skull base, within the spine and over the cerebral convexities. ${ }^{[40,41]}$ Patients with CSF flow obstruction confirmed by radionuclide show shorter survival time when compared with those with normal CSF flow. ${ }^{[42,43]}$ Managements of affected areas radiotherapy to the location of CSF flow obstruction resume flow in $30 \%$ of patients with spinal affected and in $50 \%$ of patients with intracranial involved. ${ }^{[44]}$

\section{TREATMENT}

Treatment of MC focuses on two aspects: therapy toward meningeal involvement and toward the primary cancer. In other words, patients with MC were given meningeal involvement therapy based on the primary cancer. As almost all patients with MC have been in advanced stage at presentation, palliative treatment such as radiotherapy, chemotherapy, biotherapy and molecular targeted therapy, etc. are usually the main treatment for primary tumor. Current treatments for meningeal involvement include surgery, radiation therapy (RT), systemic therapy, and intrathecal therapy, molecular targeted therapy and immunotherapy. Treatment should be targeted at alleviating the neurological symptoms, improving the quality of life and prolonging the survival time for the patients with MC. Therapy toward meningeal involvement mainly from the following aspects introduced.

\section{Surgery}

The main operative treatment in MC is ventriculoperitoneal shunting for hydrocephalus due to CSF circulatory disorders and implantation of intraventricular reservoir for administration of cytotoxic chemotherapy drugs. Communicating hydrocephalus often occurs in patients with MC leading to symptoms of intracranial hypertension. Increased intracranial pressure can be relieved by surgery with a ventriculoperitoneal shunt to improve clinical symptoms if hydrocephalus continues. If possible, an on-off valve may be placed to permit the administration of intra-CSF chemotherapy. ${ }^{[45,46]}$
Moreover, lumboperitoneal shunting may also be a therapeutic option in relieving clinical symptoms of intracranial hypertension in MC. ${ }^{[47,48]}$ There are two types of reservoirs that be generally inserted in a region in the right frontal lobe: the Rickham reservoir, which be placed over a burr hole, and the Ommaya reservoir, a domed shape device that could be easily palpated. ${ }^{[49]}$ The objective is to ensure a more uniform distribution of the drug within the subarachnoid space and to improve the curative effect of drug.

\section{Radiotherapy}

Radiotherapy is an integral part of MC therapy for patients with a syndrome of cauda equina, coexisting parenchymal brain metastases and CSF flow disturbance, which will alleviate symptoms, reduce bulky tumors volume and rectify CSF flow obstructions. Irradiation range of the whole brain irradiation (WBRT) include the cerebral meninges, basis cranii, basilar cistern, and the spinal canal to the plane of cervical vertebrae 1 and 2. WBRT is usually recommended at a dose of 30-36 Gy in fractions of $3 \mathrm{~Gy}, 40 \mathrm{~Gy}$ in $2 \mathrm{~Gy}$ fractions administered to patients with favorable prognosis, ${ }^{[45]}$ for cases with a poor prognosis $5 \times 4 \mathrm{~Gy}$ is an alternative to shortens the course of treatment. ${ }^{[50]}$ It relieved pain and alleviated nervous system symptom but demonstrated no benefit to improve survival. ${ }^{[34]}$ Craniospinal irradiation is rarely administered in MC because of its significant bone marrow toxicity. Focal radiotherapy can be administered safely in patients with bulky disease and obstructive lesions in short periods using a single dose via stereotactic radiosurgery, which is beneficial for patients with obvious syndrome of radicular pain and can result in reduced use of pain medicine. ${ }^{[45]}$ In general, symptoms usually can be controlled after RT. ${ }^{[51,52]}$

\section{Chemotherapy}

Intrathecal therapy

Intrathecal chemotherapy is generally regarded as a modality to evade the blood-brain barrier (BBB) and blood-CSF barriers in MC. Four chemotherapy agents are received FDA approval for intrathecal injection: methotrexate (MTX), cytosine arabinoside (Ara-C), liposomal Ara-C, and thiotepa, with methotrexate as the broadest used drug in the treatment of MC. As antimetabolites, MTX and Ara-C are the firm rock in medical practice for $\mathrm{MC}$ caused by any primary cancer in decades. Liposomal Ara-C has similar curative effect, but its advantage lies in decreased frequency of intrathecal injection. ${ }^{[53]}$ Additionally, trastuzumab and topotecan has recently been used in intrathecal chemotherapy in MC from breast cancer. ${ }^{[54-56]}$ Topotecan, an alkylating agent, showed variable 
effects. ${ }^{[57]}$ A retrospective review of 149 patients with breast cancer-related MC showed that there was no significant difference in overall survival between patients treated with intra-CSF liposomal cytarabine and methotrexate, with the median overall survival of 4.2 months. ${ }^{[58]}$

Other retrospective studies demonstrated similar overall survival (OS) and remission rates with one intrathecally administered agent. ${ }^{[59]}$ In addition, randomized studies showed that there was no difference in response of combined medicines (methotrexate, thiotepa, and cytarabine or methotrexate and cytarabine) and single-agent methotrexate in patients with MC. ${ }^{[60-62]}$ Therapeutic effects in patients treated with intrathecal injection may be superior to those without IT treatment $(P=$ $0.001) \cdot{ }^{[34,35]}$ Bone marrow suppression can occur after administration of intrathecal chemotherapies, which will be relieved after rescue with folinic acid $(10 \mathrm{mg}$ every $6 \mathrm{~h}$ for $24 \mathrm{~h}$ ). Intra-CSF chemotherapy usually produces transient ( $<5$ days) chemical aseptic meningitis that manifest as fever, headache, nausea/ vomiting, photophobia, meningismus and insanity, which may be mitigated by oral medications such as febrifuges, antemetics, and steroids in most cases.

Intrathecal administration of chemotherapy can be carried out either via spinal punctures or an intraventricular route. IT treatment can be performed by repeated lumbar puncture. Posture impacts ventricular drug levels after intralumbar administration and patients should remain prostration for at least one hour following treatment. Intraventricular administration of chemotherapeutic agents via an Ommaya or Rickham reservoir provide a couple of advantages compared with intralumbar treatment. ${ }^{[63]}$ The process is indolent for the patients and would help physician be more efficient during clinical practice. In addition, IV administration also shows several advantages in pharmacokinetics which can make the drugs distribute uniformly in the entire subarachnoid ventricular spaces. ${ }^{[64]}$ An improved OS was obtained for intraventricular administration compared with intralumbar chemotherapy in one clinical study of breast cancer patients with MC. ${ }^{[65]}$

Methotrexate. MTX is an anti-folate agent that inhibits dihydrofolate reductase necessary for the synthesis of folic acid required for DNA synthesis and tumor growth. The half-life of MTX is around 4-8 h. MTX is administered on a twice-weekly schedule for treatment induction and followed by weekly administration for consolidation. The following schedules have been recommended. MTX induction: 10-15 mg twice a week for 4 weeks. Consolidation: 10-15 mg once a week for 1 month and then every 2 weeks for 2 months. Maintenance: 10-15 mg every 4-8 weeks. For patients with intraventricular devices, the dose is cut in half. A retrospective study indicated that use of intensive-dose MTX therapy (15 mg/day, 5/7 days, 1 week on 1 week off) in MC patients with breast cancer had a median survival of $4.5-5$ months. ${ }^{[37]}$ Intra-CSF MTX eliminates tumor cells in $20-61 \%$ of cases with MC. ${ }^{[6]}$ IT MTX treatment in the 1st month can achieve a cytological response predictive of a longer median survival (6 vs. 2 months). ${ }^{[67]}$

Cytosine arabinoside. Ara-C, a pyrimidine analogue, inhibits the synthesis of DNA. The half-life of ara-C is approximately $3.4 \mathrm{~h}$ in the CSF, which is much longer than in serum because the cytidine deaminase is low in CSF. The traditional ara-C will be completely cleared from the CSF within 1-2 days. ${ }^{[68]}$ Similar to MTX, ara-C should be administered twice a week for treatment induction. Ara-C is relatively ineffective for MC secondary to solid tumors, but is a well established treatment for lymphomatous meningitis. Liposomal ara-C, a depot encapsulated form of ara-C (DepoCyt), provides a therapeutic ara-C concentration in the CSF for as many as 10-12 days with a half-life of $140 \mathrm{~h}$. Intra-CSF administration of the liposomal ara-C may be once every 2 weeks. A randomized trial analyzed the survival rate difference in solid tumor-related MC treated with intra-CSF liposomal ara-C and MTX and there was no marked significant difference between the two groups (median survival 105 vs. 78 days). ${ }^{[69]}$ The improvement in median time to neurologic progression with intra-CSF liposomal ara-C administration improved neurologic progression free survival (PFS) and reduced times of hospitalization for patients. ${ }^{[70]}$ The schedule of intra-CSF administration as follows: liposomal ara-C induction: $50 \mathrm{mg}$ every 2 weeks in weeks 1 and 3 . Consolidation: $50 \mathrm{mg}$ every 2 weeks in weeks 5,7 and 9, followed by an additional dose at week 13 . Maintenance: $50 \mathrm{mg}$ every 4 weeks in weeks 17, 21, 25 and 29. Ara- $C$ is initially administered at a dosage of $25-100 \mathrm{mg}$ twice weekly with a 4-week induction, followed by $25-100 \mathrm{mg}$ once weekly for 4 weeks of consolidation and $25-100 \mathrm{mg}$ once a month for subsequent maintenance. If cytarabine is delivered intraventricularly, a dose reduction of $50 \%$ should be considered.

Thiotepa. Thiotepa, an alkylating agent, inhibits the cell cycle nonspecifically and available for routine intra-CSF chemotherapy. It shows the shortest halflife of all drugs used for intra-CSF chemotherapy with approximately $20 \mathrm{~min}$ and is cleared completely 
in CSF within $4 \mathrm{~h}$.

Intrathecal administration of thiotepa may be used in second-line treatment regimens for breast cancerrelated MC patients who show poor response or fail to tolerate intra-CSF MTX. A randomized trial demonstrated that MC patients treated with intraCSF MTX had significantly longer median survival compared with intra-CSF thiotepa (16 vs. 14 weeks). ${ }^{71]}$ Thiotepa Induction: $10 \mathrm{mg} 2$ or 3 times weekly for 4 weeks. Consolidation: $10 \mathrm{mg}$ once weekly for 4 weeks. Maintenance: $10 \mathrm{mg}$ once a month.

Innovative intra-CSF chemotherapy regimens. The growing number of patients with tumor who develop MC boost the investigation of new intra-CSF chemotherapeutic agents such as topotecan, alpha interferon, trastuzumab, rituximab.

(1) Topotecan. Topotecan, a topoisomerase I inhibitor, shows anticancer activity against various solid tumors of adult and childhood. A phase I study has shown a response in 3 out of 13 children received IT topotecan with primary brain tumors-related MC. ${ }^{[72]}$ It is not clear if Topotecan, with good tolerability, produces any added benefit compared to other intra-CSF therapies. Therefore, IVent topotecan combined with other IVent agents may be an option due to its good tolerance profile. The treatment program is as follows. Induction: $0.4 \mathrm{mg}$ twice a week for 6 weeks. Consolidation: 0.4 mg twice a week for 6 additional doses. Maintenance: 0.4 mg twice monthly for 4 months and then monthly thereafter; (2) biological modifiers. Intra-CSF administration of interleukin-2 has been evaluated in cases with MC secondary to melanoma. As previously reported with systemic therapy, some cases showed a long-term clinical response but some side-effects of therapy appeared. ${ }^{[73]}$ In addition, interferon-alpha exhibited a moderate activity in a phase II trial of 22 patients with MC from a wide variety of solid tumor (median period of response: 16 weeks), combined with a transient chemical arachnoiditis and cumulative fatigue in most cases; ${ }^{[74]}$ (3) monoclonal antibodies. In clinical studies, intra-CSF administration of monoclonal antibodies which targets the tumor antigens have been performed in patients with $\mathrm{MC}$ from solid tumors including breast cancer, ovarian cancer, melanoma and showed a rare long period of response (7-26 months). ${ }^{[75]}$

Trastuzumab. Approximately $3-5 \%$ of HER 2 positive breast cancer patients develop meningeal metastasis unlike the parenchymal brain metastasis (about 30\%). ${ }^{[6,77]}$ Primary tumor tissues and CSF neoplastic cell share tumor HER 2 status. ${ }^{[78]}$ Trastuzumab CSF/serum ratios vary from $0.0023 \mathrm{mg} / \mathrm{dL}$ to
$0.02 \mathrm{mg} / \mathrm{dL}$ in patients with MC regardless of WBRT, which result in very limited CSF concentration of trastuzumab. ${ }^{[79,80]}$ The clinical practice of intraCSF trastuzumab shows clinical and cytological success in patients with MC from HER-2 positive breast cancer. ${ }^{[81,82]} \mathrm{A}$ patient with $\mathrm{MC}$ received 67 cycles of weekly $25 \mathrm{mg}$ IT trastuzumab with a long survival time (27 months) after MC diagnosis and dramatic clinical improvement. ${ }^{[54]}$ Moreover, intraCSF trastuzumab combined with intra-CSF MTX and ara-C has been performed in two patients with MC. The survival time of the two patients was 13.5 months and 6 months respectively with a clinical benefit and without substantial toxicity. ${ }^{[55]}$ Intra-CSF administration of trastuzumab remains experimental and additional experience and data are required before consideration as a standard treatment.

Bevacizumab. Bevacizumab, an angiogenic inhibitor, target the VEGF ligand. Several studies showed higher levels of VEGF in CSF in patients with MC, supporting the hypothesis that angiogenesis promotes $\mathrm{MC}$. The correlation coefficient was negative between VEGF and survival in these patients. ${ }^{\left[{ }^{83,84]}\right.}$ Bevacizumab is clinically approved metastatic colorectal cancer and NSCLC. Retrospective study manifested that bevacizumab was found to be safe in CNS metastases without inducing intracranial hemorrhage. ${ }^{[85]}$ The assessment of intra-CSF injection of bevacizumab is ongoing in $M C .{ }^{[86,87]}$ A pilot study of 15 patients with $M C$ showed that bevacizumab resulted in a dramatically decreased CSF VEGF level and relief of clinical symptoms. Furthermore, a preclinical rabbit model of MC treated with intra-CSF bevacizumab has been evaluated. ${ }^{[88]}$

\section{Systemic chemotherapy}

The advantage of intra-CSF chemotherapy in solid tumors-related MC pales in comparison to hematological malignant tumor because of inborn chemical resistance, limited intra-CSF chemotherapy drugs availability, and the insufficient accessibility of large nodules to intra-CSF chemotherapy. In addition, $\mathrm{MC}$ is always accompanied with systemic disease, so it is reasonable to use systemic chemotherapy to simultaneously treat systemic disease and MC. ${ }^{[89,90]}$ Treatment options of intra-CSF and systemic chemotherapy have been evaluated in solid tumorsrelated $M C .{ }^{[91,92]}$ The overall response rate, the long-term survival rate and the median survival of patients with solid tumors-related MC who underwent intra-CSF chemotherapy combined with systemic chemotherapy and radiotherapy did not change despite increased neurotoxicity. Another prospective 
study in patients with MC from NSCLC concluded that adding systemic chemotherapy to combined intraCSF chemotherapy and radiotherapy did not improve the survival time due to insensitivity of the type of cancer. ${ }^{[93]}$ Data from a retrospective study of 135 patients showed that the management of systemic chemotherapy is closely related to a longer survival time, which is a significant positive prognostic factors in patients with MC. ${ }^{[94]}$ However, the choice of the systemic chemotherapy seems to be based not only on the chemical sensitivity of the primary tumor but also on its ability to pass through the blood-brainbarrier and the effective concentrations of drug in the CSF, which can image the chemical characteristics of the systemic agent. Treatment with high-dose intravenous MTX and cytarabine achieved therapeutic CSF levels in patients with hematological malignancy and $\mathrm{MC}$ from breast cancer. ${ }^{[22]}$

Myelosuppression is the dose-limiting factor of these treatment schedules. Moreover, these agents are toxic and limited by their narrow spectrum of activity in most solid tumors.

\section{Molecular targeted therapy}

Recently, the application of molecular targeted drugs in the clinic have achieved breakthrough results in patients with MC who show mutations in the EGFR gene or rearrangement of the anaplastic lymphoma kinase $(A L K)$ gene in lung tumor, amplification of human epidermal growth factor receptor 2 (HER2) gene in breast cancer, and positivity of CD20 in B cell lymphoma.

Mutations in the EGFR gene and rearrangement of the $A L K$ gene are the two the most frequently studied types of genetic mutations in NSCLC. Identification of the mutation status of the EGFR gene is crucial because patients harboring EGFR gene mutations are highly sensitive to EGFR tyrosine kinase inhibitor (TKI). EGFR mutations are independent positive prognostic factors in patients with NSCLC-related MC. ${ }^{[95,96]}$ Liao et al. ${ }^{[97]}$ indicated that MC patients receiving EGFR TKI therapy with an EGFR mutation showed longer overall survival compared with those without the mutation (10.9 months vs. 2.3 months, $P<0.001)$. EGFR TKI can pass through the BBB at levels of $1-3 \% \cdot{ }^{[98]}$ A study demonstrated that high-dose gefitinib (750 or $1,000 \mathrm{mg}$ daily) improves neurologic symptoms and achieve therapeutic levels in CSF in $57 \%$ of NSCLC patients with MC who is sensitive to EGFR TKI. ${ }^{[99]}$ Erlotinib showed higher concentration in CSF (28.7 vs. $3.7 \mathrm{ng} / \mathrm{mL}, P=0.0008$ ) compared to gefitinib. ${ }^{[98]}$ Moreover, a retrospective study indicated that the cytologic transformation rates in erlotinib treatment group were higher $(64.3 \%$ vs. $9.1 \%, P$ $=0.012$ ) than gefitinib treatment group in NSCLC with MC. ${ }^{[100]}$ In addition, afatinib is an FDA-approved second-generation EGFR TKI for NSCLC with EGFR mutations and the effective treatment for CNS metastasis (brain metastasis or MC) in NSCLC who had an inadequate response to erlotinib or gefitinib. ${ }^{101]}$ However, there are no reports of the curative effect of afatinib in patients with $M C$ who failed high-dose EGFR TKI. Osimertinib (AZD9291), a third-generation EGFR TKI, showed effectiveness in an in vivo MC model with a first-and second-generation EGFR TKI resistant. ${ }^{[102]}$

Rearrangement of the $A L K$ gene is observed in around $4-5 \%$ of NSCLC patients. Identifying ALK rearrangement is important because patients with rearrangement of the $A L K$ gene can be effectively treated with $A L K$ inhibitors. ${ }^{[103]}$ Crizotinib, a firstgeneration $A L K$ inhibitor, shows poorly BBB permeability with a CSF-to-plasma ratio of 0.026 , so the CNS remains a frequent site of recurrence for $A L K$ positive cases treated with crizotinib. ${ }^{[104,105]}$ Several case reports showed a higher brain-to-plasma ratio of the second-generation ALK inhibitors (ceritinib or alectinib) compared to first-generation $A L K$ inhibitors and better efficacy against MC for $A L K$ positive patients with brain metastases. ${ }^{[106-108]}$ Evidence from studies show that second-generation ALK inhibitors, especially ceritinib, may be treatment choices in MC patients from ALK-positive NSCLC. ${ }^{[109]}$

Amplification of HER2 is found in about $15-20 \%$ of breast cancer cases.

Trastuzumab is a monoclonal antibody that acts via the HER2 receptor and is effective for patients with HER2-positive breast cancer. ${ }^{[110]}$ However, the effects have been limited due to BBB permeability in MC. Stemmler et al. ${ }^{[79]}$ found that the ratio of serum trastuzumab to CSF trastuzumab in patients with brain metastases from breast cancer was 420:1 before radiation, 76:1 after radiotherapy, and 49:1 in cases with accompanied MC after radiotherapy. Trastuzumab is a highly effective intrathecal chemotherapy agent that can be used independently, or in combination with other drugs, for the management of $\mathrm{MC}$ from HER2-positive breast cancer. ${ }^{[55,111,112]}$ Several studies revealed that intrathecal trastuzumab can be used safely and efficiently for HER2-postive breast cancer patients with $\mathrm{MC}$ with a wide dose range of 4-150 mg. ${ }^{[13]}$ Lapatinib, as a dual TKI of HER1 and HER2 is effective for HER2-positive breast cancer patients who have progressed while on trastuzumab. ${ }^{[114,115]}$ Nevertheless, there has been no reported data on lapatinib for 
treatment of MC. Therefore, intrathecal trastuzumab is the only targeted therapy for $\mathrm{MC}$ in patients with HER2-positive breast cancer.

Rituximab, an anti-CD20 monoclonal antibody, shows efficacy in patients with diffuse large-B-cell lymphoma, its effects in $M C$ are limited because of its large molecular size leading clinicians to study intrathecal rituximab. ${ }^{[116-118]}$ A case-series analysis of relapsed CNS lymphoma demonstrated that intraventricular administration of rituximab showed efficacy in six cases. Intraventricular rituximab was administered in dose of $10-40 \mathrm{mg}$, produced a total elimination rate of malignant cells in CSF for three patients and a disappearance of leptomeningeal lymphoma nodules in one patient. ${ }^{[118]}$ Therefore, these results show the potential of intrathecal rituximab for patients of MC with CD20-positive lymphoma.

Vemurafenib, a BRAF inhibitors, possesses a good perspective in late stage of melanoma patients with BRAF mutatation. In a case report, vemurafenib showed clinical and imaging responses and improvement of survival time. ${ }^{[119]}$

\section{Immunotherapy}

CpG-28, a Toll-like receptor 9 (TLR-9) agonist, can boost both the innate and the adaptive immune system through stimulation of TLR-9 and have antineoplastic activity in animal models. ${ }^{[120]}$ In a phase I trial, 29 patients with MC received injection of CpG-28 both subcutaneously and intrathecally, which indicated the tolerance and feasibility of intrathecal injection with CpG-ODN for cases with MC. ${ }^{[121]}$ The median PFS was 7 weeks and OS was 15 weeks. This new immunostimulating agent was also used in patients with recurrent glioblastoma, which showed good security and some cases of mild reactions. ${ }^{[122,123]}$ Based on the current study results from each phase of clinical trials, immunotherapy has become a new direction of clinical researches on MC.

\section{CONCLUSION}

MC is the third most common CNS metastatic complication of systemic cancer with extremely poor prognosis. We summarized the epidemiology, pathophysiology, clinical manifestation, diagnosis and various therapeutic managements for solid tumorrelated MC. The symptomatology is characterized by high intracranial pressure (headache, nausea, vomiting, consciousness disorder), cranial nerve involvement and radicular symptoms. The correct diagnosis depends on the contrast-enhanced magnetic resonance imaging of the spine and brain in combination with the cytological CSF analysis. In addition, the technology of high-throughput sequencing of CSF which recognizes cancerrelated DNA will provide significant reference for the diagnosis in clinics. Traditional treatments including surgery, RT, systemic chemotherapy and intrathecal chemotherapy, but the prognosis for MC remains very poor with a median survival of < 3 months. Recently, molecular targeting treatment and immunotherapy have been applied to $M C$ and have shown breakthrough results. The prognosis of MC may be affected by several factors such as age, performance status, primary tumor histology. Age of more than 50, low Karnofsky performance status, lung cancer or malignant melanoma as primary tumor may be the negative prognostic factors in cases with $\mathrm{MC}$. Therefore, precise diagnostic techniques remain to be investigated, and novel therapeutic targets need to be found to improve the life quality and prolong the survival time for the patients with MC.

\section{DECLARATIONS}

\section{Authors' contributions}

Study concept and design: J.Y. He

Manuscript drafting: J.Z. Cui

Manuscript revising: Q. Li

Data collection: X.Q. Li, R.P. Gao, H. Bu

Literature search: Y.L. Zou, X.S. Guo, W.X. Han, Z.Y. Zhao, Y.Y. Li, M.M. Zheng, Y.J. Liu, L.T. Yan

\section{Financial support and sponsorship} None.

\section{Conflicts of interest}

There are no conflicts of interest.

\section{Patient consent}

There is no patient data involved.

\section{Ethics approval}

Not applicable.

\section{REFERENCES}

1. Zhu H. The importance of immunocytochemistry in diagnosing meningeal carcinomatosis. Chin J Med 2003;2:580.

2. Jorda M, Ganjei-Azar P, Nadji M. Cytologic characteristics of meningeal carcinomatosis: increased diagnostic accuracy using carcinoembryonic antigen and epithelial membrane antigen immunocytochemistry. Arch Neurol 1998;55:181-4.

3. Oschmann P, Kaps M, Volker J, Dorndorf W. Meningeal carcinomatosis: CSF cytology, immunocytochemistry and biochemical tumor markers. Acta Neurol Scand 1994;89:395-9.

4. $\mathrm{Hu}$ F, Shao H, Guo L, Lu S. The value of cerebrospinal fluid (CSF) cytological checkup in diagnosing meningeal carcinomatosis. Chin J Neurol 2000;33:9. 
5. Eberth CJ. Zur Entwickelung des Epithelioms (Cholesteatoms) der Pia und der Lunge. Arch Pathol Anat Physiol Klin Med 1870;49:51-63.

6. Weil RJ, Palmieri DC, Bronder JL, Stark AM, Steeg PS. Breast cancer metastasis to the central nervous system. Am J Pathol 2005;167:913-20.

7. Aragon-Ching JB, Zujewski JA. CNS metastasis: an old problem in a new guise. Clin Cancer Res 2007;13:1644-7.

8. Chamberlain MC. Neoplastic meningitis. Curr Neurol Neurosci Rep 2008;8:249-58.

9. Pace A, Fabi A. Chemotherapy in neoplastic meningitis. Crit Rev Oncol Hematol 2006;60:194-200.

10. Kesari S, Batchelor TT. Leptomeningeal metastases. Neurol Clin 2003;21:25-66.

11. Clarke JL, Perez HR, Jacks LM, Panageas KS, Deangelis LM. Leptomeningeal metastases in the MRI era. Neurology 2010;74:1449-54.

12. Beauchesne P. Intrathecal chemotherapy for treatment of leptomeningeal dissemination of metastatic tumours. Lancet Oncol 2010;11:871-9.

13. Brem SS, Bierman PJ, Brem H, Butowski N, Chamberlain MC, Chiocca EA, DeAngelis LM, Fenstermaker RA, Friedman A, Gilbert MR, Hesser D, Junck L, Linette GP, Loeffler JS, Maor MH, Michael M, Moots PL, Morrison T, Mrugala M, Nabors LB, Newton HB, Portnow J, Raizer JJ, Recht L, Shrieve DC, Sills AK Jr, Vrionis FD, Wen PY. Central nervous system cancers. J Natl Compr Canc Netw 2011;9:352-400.

14. de Azevedo CR, Cruz MR, Chinen LT, Peres SV, Peterlevitz MA, de Azevedo Pereira AE, Fanelli MF, Gimenes DL. Meningeal carcinomatosis in breast cancer: prognostic factors and outcome. $J$ Neurooncol 2011;104:565-72.

15. Chamberlain MC. Neoplastic meningitis. J Clin Oncol 2005;23:3605-13.

16. Chamberlain MC, Glantz M, Groves MD, Wilson WH. Diagnostic tools for neoplastic meningitis: detecting disease, identifying patient risk, and determining benefit of treatment. Semin Oncol 2009;36:S35-45.

17. Jaeckle KA. Neoplastic meningitis from systemic malignancies: diagnosis, prognosis and treatment. Semin Oncol 2006;33:312-23.

18. Chamberlain MC. Leptomeningeal metastasis. Curr Opin Oncol 2010;22:627-35.

19. Guan H, Wang C, Guo Y, Chen L, Ren H, Zhao H. Specific findings in cerebrospional fluid cytology. Chin J Neurol 2004;37:65-7.

20. Chamberlain MC. Neoplastic meningitis. Oncologist 2008;13:967-77.

21. He J, Chen Q, Liu K, Wang L, Ynag X, Zou Y. Early diagnosis of patients with meningeal carcinomatosis with earcino-embryonic antigen hnmunocytochemical stain examination and laser scanning confocal microscope. Chin J Neurol 2009;42:412-6.

22. Glantz MJ, Cole BF, Recht L, Akerley W, Mills P, Saris S, Hochberg F, Calabresi P, Egorin MJ. High-dose intravenous methotrexate for patients with nonleukemic leptomeningeal cancer: is intrathecal chemotherapy necessary? J Clin Oncol 1998;16:1561-7.

23. Wasserstrom WR, Schwartz MK, Fleisher M, Posner JB. Cerebrospinal fluid biochemical markers in central nervous system tumors: a review. Ann Clin Lab Sci 1981;11:239-51.

24. Stockhammer G, Poewe W, Burgstaller S, Deisenhammer F, Muigg A, Kiechl S, Schmutzhard E, Maier H, Felber S, Schumacher P, Gunsilius E, Gastl G. Vascular endothelial growth factor in CSF: a biological marker for carcinomatous meningitis. Neurology 2000;54:1670-6.

25. Gauchez AS, Pez E, Boutonnat J, Bourre JC, Pelletier L, Payan R, Mousseau M. Early detection of leptomeningeal metastasis in patients with metastatic breast carcinoma: validation of CA 15-3 measurement in cerebrospinal fluid. Ann Biol Clin (Paris) 2007;65:653-8.

26. Groves MD, Hess KR, Puduvalli VK, Colman H, Conrad CA, Gilbert
MR, Weinberg J, Cristofanilli M, Yung WK, Liu TJ. Biomarkers of disease: cerebrospinal fluid vascular endothelial growth factor (VEGF) and stromal cell derived factor (SDF)-1 levels in patients with neoplastic meningitis (NM) due to breast cancer, lung cancer and melanoma. J Neurooncol 2009;94:229-34

27. Orphanos G, Ioannidis G, Michael M, Kitrou G. Prostate-specific antigen in the cerebrospinal fluid: a marker of local disease. Med Oncol 2009;26:143-6.

28. Chamberlain MC. Cytologically negative carcinomatous meningitis: usefulness of CSF biochemical markers. Neurology 1998;50:1173-5.

29. Sasaki S, Yoshioka Y, Ko R, Katsura Y, Namba Y, Shukuya T, Kido $\mathrm{K}$, Iwakami S, Tominaga S, Takahashi K. Diagnostic significance of cerebrospinal fluid EGFR mutation analysis for leptomeningeal metastasis in non-small-cell lung cancer patients harboring an active EGFR mutation following gefitinib therapy failure. Respir Investig 2016;54:14-9.

30. Pentsova EI, Shah RH, Tang J, Boire A, You D, Briggs S, Omuro A, Lin X, Fleisher M, Grommes C, Panageas KS, Meng F, Selcuklu SD, Ogilvie S, Distefano N, Shagabayeva L, Rosenblum M, DeAngelis LM, Viale A, Mellinghoff IK, Berger MF. Evaluating cancer of the central nervous system through next-generation sequencing of cerebrospinal fluid. J Clin Oncol 2016;34:2404-15.

31. Dietemann JL, Correia Bernardo R, Bogorin A, Abu Eid M, Koob M Nogueira T, Vargas MI, Fakhoury W, Zollner G. Normal and abnorma meningeal enhancement: MRI features. J Radiol 2005;86:1659-83.

32. Gauthier H, Guilhaume MN, Bidard FC, Pierga JY, Girre V, Cottu PH, Laurence V, Livartowski A, Mignot L, Dieras V. Survival of breast cancer patients with meningeal carcinomatosis. Ann Oncol 2010;21:2183-7.

33. Chamberlain MC, Johnston SK. Neoplastic meningitis: survival as a function of cerebrospinal fluid cytology. Cancer 2009;115:1941-6.

34. Morris PG, Reiner AS, Szenberg OR, Clarke JL, Panageas KS, Perez HR, Kris MG, Chan TA, DeAngelis LM, Omuro AM. Leptomeningeal metastasis from non-small cell lung cancer: survival and the impact of whole brain radiotherapy. $J$ Thorac Oncol 2012;7:382-5.

35. Park JH, Kim YJ, Lee JO, Lee KW, Kim JH, Bang SM, Chung JH, Kim JS, Lee JS. Clinical outcomes of leptomeningeal metastasis in patients with non-small cell lung cancer in the modern chemotherapy era. Lung Cancer 2012;76:387-92.

36. Rudnicka H, Niwinska A, Murawska M. Breast cancer leptomeningeal metastasis -- the role of multimodality treatment. J Neurooncol 2007;84:57-62.

37. Clatot F, Philippin-Lauridant G, Ouvrier MJ, Nakry T, Laberge-LeCouteulx S, Guillemet C, Veyret C, Blot E. Clinical improvement and survival in breast cancer leptomeningeal metastasis correlate with the cytologic response to intrathecal chemotherapy. J Neurooncol 2009;95:421-6.

38. Mittl RL Jr, Yousem DM. Frequency of unexplained meningeal enhancement in the brain after lumbar puncture. AJNR Am J Neuroradiol 1994;15:633-8.

39. Chamberlain MC. Radioisotope CSF flow studies in leptomeningeal metastases. J Neurooncol 1998;38:135-40.

40. Glantz MJ, Hall WA, Cole BF, Chozick BS, Shannon CM, Wahlberg L, Akerley W, Marin L, Choy H. Diagnosis, management, and survival of patients with leptomeningeal cancer based on cerebrospinal fluidflow status. Cancer 1995;75:2919-31.

41. Chamberlain MC. Comparative spine imaging in leptomeningeal metastases. J Neurooncol 1995;23:233-8.

42. Chamberlain MC, Kormanik PA. Prognostic significance of 111 indium-DTPA CSF flow studies in leptomeningeal metastases. Neurology 1996;46:1674-7.

43. Mason WP, Yeh SD, DeAngelis LM. 111Indium-diethylenetriamine pentaacetic acid cerebrospinal fluid flow studies predict distribution of 
intrathecally administered chemotherapy and outcome in patients with leptomeningeal metastases. Neurology 1998;50:438-44.

44. Chamberlain MC, Corey-Bloom J. Leptomeningeal metastases: 111 indium-DTPA CSF flow studies. Neurology 1991;41:1765-9.

45. DeAngelis LM. Current diagnosis and treatment of leptomeningeal metastasis. J Neurooncol 1998;38:245-52.

46. Lin N, Dunn IF, Glantz M, Allison DL, Jensen R, Johnson MD, Friedlander RM, Kesari S. Benefit of ventriculoperitoneal cerebrospinal fluid shunting and intrathecal chemotherapy in neoplastic meningitis: a retrospective, case-controlled study. J Neurosurg 2011;115:730-6.

47. Zhang XH, Wang XG, Piao YZ, Wang P, Li P, Li WL. Lumboperitoneal shunt for the treatment of leptomeningeal metastasis. Med Hypotheses 2015;84:506-8.

48. Yamashiro S, Hitoshi Y, Tajiri S, Uchikawa H, Ito K, Yoshida A, Kuratsu JI. Palliative lumboperitoneal shunt for leptomeningeal metastasis-related hydrocephalus: a case series. Palliat Med 2017;31:93-6.

49. Sandberg DI, Bilsky MH, Souweidane MM, Bzdil J, Gutin PH. Ommaya reservoirs for the treatment of leptomeningeal metastases. Neurosurgery 2000;47:49-54; discussion 54-5.

50. Souchon R, Feyer P, Thomssen C, Fehm T, Diel I, Nitz U, Janni W, Bischoff J, Sauer R. Clinical recommendations of DEGRO and AGO on preferred standard palliative radiotherapy of bone and cerebral metastases, metastatic spinal cord compression, and leptomeningeal carcinomatosis in breast cancer. Breast Care (Basel) 2010;5:401-7.

51. Brem SS, Bierman PJ, Black P, Blumenthal DT, Brem H, Chamberlain MC, Chiocca EA, DeAngelis LM, Fenstermaker RA, Fine HA, Friedman A, Glass J, Grossman SA, Heimberger AB, Junck L, Levin V, Loeffler JJ, Maor MH, Narayana A, Newton HB, Olivi A, Portnow J, Prados M, Raizer JJ, Rosenfeld SS, Shrieve DC, Sills AK, Jr., Spence AM, Vrionis FD. Central nervous system cancers: clinical practice guidelines in oncology. J Natl Compr Canc Netw 2005;3:644-90.

52. Salgia S, Fleming GF, Lukas RV. Leptomeningeal carcinomatosis from breast cancer treated with intrathecal topotecan with concomitant intravenous eribulin. J Clin Neurosci 2014;21:1250-1.

53. Glantz MJ, Jaeckle KA, Chamberlain MC, Phuphanich S, Recht L, Swinnen LJ, Maria B, LaFollette S, Schumann GB, Cole BF, Howell $\mathrm{SB}$. A randomized controlled trial comparing intrathecal sustainedrelease cytarabine (DepoCyt) to intrathecal methotrexate in patients with neoplastic meningitis from solid tumors. Clin Cancer Res 1999;5:3394-402.

54. Oliveira M, Braga S, Passos-Coelho JL, Fonseca R, Oliveira J. Complete response in HER2+ leptomeningeal carcinomatosis from breast cancer with intrathecal trastuzumab. Breast Cancer Res Treat 2011;127:841-4.

55. Mego M, Sycova-Mila Z, Obertova J, Rajec J, Liskova S, Palacka P, Porsok S, Mardiak J. Intrathecal administration of trastuzumab with cytarabine and methotrexate in breast cancer patients with leptomeningeal carcinomatosis. Breast 2011;20:478-80.

56. Chang EL, Lo S. Diagnosis and management of central nervous system metastases from breast cancer. Oncologist 2003;8:398-410.

57. Groves MD, Glantz MJ, Chamberlain MC, Baumgartner KE, Conrad CA, Hsu S, Wefel JS, Gilbert MR, Ictech S, Hunter KU, Forman AD, Puduvalli VK, Colman H, Hess KR, Yung WK. A multicenter phase II trial of intrathecal topotecan in patients with meningeal malignancies. Neuro Oncol 2008;10:208-15.

58. Niwinska A. Brain metastases as site of first and isolated recurrence of breast cancer: the role of systemic therapy after local treatment. Clin Exp Metastasis 2016;33:677-85.

59. Chamberlain M, Soffietti R, Raizer J, Ruda R, Brandsma D, Boogerd W, Taillibert S, Groves MD, Le Rhun E, Junck L, van den Bent M, Wen PY, Jaeckle KA. Leptomeningeal metastasis: a Response
Assessment in Neuro-Oncology critical review of endpoints and response criteria of published randomized clinical trials. Neuro Oncol 2014; $16: 1176-85$.

60. Hitchins RN, Bell DR, Woods RL, Levi JA. A prospective randomized trial of single-agent versus combination chemotherapy in meningeal carcinomatosis. J Clin Oncol 1987;5:1655-62.

61. Bleyer WA, Drake JC, Chabner BA. Neurotoxicity and elevated cerebrospinal-fluid methotrexate concentration in meningeal leukemia. N Engl J Med 1973;289:770-3.

62. Giannone L, Greco FA, Hainsworth JD. Combination intraventricular chemotherapy for meningeal neoplasia. J Clin Oncol 1986;4:68-73.

63. Glantz MJ, Cole BF, Glantz LK, Cobb J, Mills P, Lekos A, Walters BC, Recht LD. Cerebrospinal fluid cytology in patients with cancer: minimizing false-negative results. Cancer 1998;82:733-9.

64. Chamberlain MC, Khatibi S, Kim JC, Howell SB, Chatelut E, Kim $\mathrm{S}$. Treatment of leptomeningeal metastasis with intraventricular administration of depot cytarabine (DTC 101). A phase I study. Arch Neurol 1993;50:261-4.

65. Ongerboer de Visser BW, Somers R, Nooyen WH, van Heerde P, Hart AA, McVie JG. Intraventricular methotrexate therapy of leptomeningeal metastasis from breast carcinoma. Neurology 1983;33:1565-72.

66. Grossman SA, Trump DL, Chen DC, Thompson G, Camargo EE. Cerebrospinal fluid flow abnormalities in patients with neoplastic meningitis. An evaluation using 111 indium-DTPA ventriculography. Am J Med 1982;73:641-7.

67. Sause WT, Crowley J, Eyre HJ, Rivkin SE, Pugh RP, Quagliana JM, Taylor SA, Molnar B. Whole brain irradiation and intrathecal methotrexate in the treatment of solid tumor leptomeningeal metastases -- a Southwest Oncology Group study. J Neurooncol 1988;6:107-12.

68. Esteva FJ, Soh LT, Holmes FA, Plunkett W, Meyers CA, Forman AD, Hortobagyi GN. Phase II trial and pharmacokinetic evaluation of cytosine arabinoside for leptomeningeal metastases from breast cancer. Cancer Chemother Pharmacol 2000;46:382-6.

69. Glantz MJ, LaFollette S, Jaeckle KA, Shapiro W, Swinnen L, Rozental JR, Phuphanich S, Rogers LR, Gutheil JC, Batchelor T, Lyter D, Chamberlain M, Maria BL, Schiffer C, Bashir R, Thomas D, Cowens W, Howell SB. Randomized trial of a slow-release versus a standard formulation of cytarabine for the intrathecal treatment of lymphomatous meningitis. J Clin Oncol 1999;17:3110-6.

70. Cole BF, Glantz MJ, Jaeckle KA, Chamberlain MC, Mackowiak JI. Quality-of-life-adjusted survival comparison of sustained-release cytosine arabinoside versus intrathecal methotrexate for treatment of solid tumor neoplastic meningitis. Cancer 2003;97:3053-60.

71. Grossman SA, Finkelstein DM, Ruckdeschel JC, Trump DL, Moynihan T, Ettinger DS. Randomized prospective comparison of intraventricular methotrexate and thiotepa in patients with previously untreated neoplastic meningitis. Eastern Cooperative Oncology Group. J Clin Oncol 1993;11:561-9.

72. Blaney SM, Heideman R, Berg S, Adamson P, Gillespie A, Geyer JR, Packer R, Matthay K, Jaeckle K, Cole D, Kuttesch N, Poplack DG, Balis FM. Phase I clinical trial of intrathecal topotecan in patients with neoplastic meningitis. J Clin Oncol 2003;21:143-7.

73. Samlowski WE, Park KJ, Galinsky RE, Ward JH, Schumann GB. Intrathecal administration of interleukin-2 for meningeal carcinomatosis due to malignant melanoma: sequential evaluation of intracranial pressure, cerebrospinal fluid cytology, and cytokine induction. J Immunother Emphasis Tumor Immunol 1993;13:49-54.

74. Chamberlain MC. A phase II trial of intra-cerebrospinal fluid alpha interferon in the treatment of neoplastic meningitis. Cancer 2002;94:2675-80.

75. Brown MT, Coleman RE, Friedman AH, Friedman HS, McLendon 
RE, Reiman R, Felsberg GJ, Tien RD, Bigner SH, Zalutsky MR, Zhao XG, Wikstrand CJ, Pegram CN, Herndon JE, 2nd, Vick NA, Paleologos N, Fredericks RK, Schold SC Jr, Bigner DD. Intrathecal 131I-labeled antitenascin monoclonal antibody 81C6 treatment of patients with leptomeningeal neoplasms or primary brain tumor resection cavities with subarachnoid communication: phase I trial results. Clin Cancer Res 1996;2:963-72.

76. Bendell JC, Domchek SM, Burstein HJ, Harris L, Younger J, Kuter I, Bunnell C, Rue M, Gelman R, Winer E. Central nervous system metastases in women who receive trastuzumab-based therapy for metastatic breast carcinoma. Cancer 2003;97:2972-7.

77. Nam BH, Kim SY, Han HS, Kwon Y, Lee KS, Kim TH, Ro J. Breast cancer subtypes and survival in patients with brain metastases. Breast Cancer Res 2008;10:R20.

78. Park IH, Kwon Y, Ro JY, Lee KS, Ro J. Concordant HER2 status between metastatic breast cancer cells in CSF and primary breast cancer tissue. Breast Cancer Res Treat 2010;123:125-8.

79. Stemmler HJ, Schmitt M, Willems A, Bernhard H, Harbeck N, Heinemann V. Ratio of trastuzumab levels in serum and cerebrospinal fluid is altered in HER2-positive breast cancer patients with brain metastases and impairment of blood-brain barrier. Anticancer Drugs 2007; 18:23-8.

80. Stemmler HJ, Schmitt M, Harbeck N, Willems A, Bernhard H, Lassig D, Schoenberg S, Heinemann V. Application of intrathecal trastuzumab (Herceptintrade mark) for treatment of meningeal carcinomatosis in HER2-overexpressing metastatic breast cancer. Oncol Rep 2006;15:1373-7.

81. Hofer S, Mengele K, Stemmler HJ, Schmitt M, Pestalozzi B. Intrathecal trastuzumab: dose matters. Acta Oncol 2012;51:955-6.

82. Mir O, Ropert S, Alexandre J, Lemare F, Goldwasser F. High-dose intrathecal trastuzumab for leptomeningeal metastases secondary to HER-2 overexpressing breast cancer. Ann Oncol 2008; 19:1978-80.

83. Groves MD. CSF levels of angiogenesis-related proteins in patients with leptomeningeal metastases. Neurology 2006;66:1609-10; author reply $1609-10$.

84. Reijneveld JC, Brandsma D, Boogerd W, Bonfrer JG, Kalmijn S, Voest EE, Geurts-Moespot A, Visser MC, Taphoorn MJ. CSF levels of angiogenesis-related proteins in patients with leptomeningeal metastases. Neurology 2005;65:1120-2.

85. Besse B, Lasserre SF, Compton P, Huang J, Augustus S, Rohr UP. Bevacizumab safety in patients with central nervous system metastases. Clin Cancer Res 2010;16:269-78.

86. De Braganca KC, Janjigian YY, Azzoli CG, Kris MG, Pietanza MC, Nolan CP, Omuro AM, Holodny AI, Lassman AB. Efficacy and safety of bevacizumab in active brain metastases from non-small cell lung cancer. J Neurooncol 2010;100:443-7.

87. Groves MD. Leptomeningeal disease. Neurosurg Clin $N$ Am 2011;22:67-78, vii.

88. Brastianos PK, Brastianos HC, Hsu W, Sciubba DM, Kosztowski T, Tyler BM, Recinos VR, Burger P, Grossman SA. The toxicity of intrathecal bevacizumab in a rabbit model of leptomeningeal carcinomatosis. J Neurooncol 2012;106:81-8.

89. Siegal T, Lossos A, Pfeffer MR. Leptomeningeal metastases: analysis of 31 patients with sustained off-therapy response following combined-modality therapy. Neurology 1994;44:1463-9.

90. Grant R, Naylor B, Greenberg HS, Junck L. Clinical outcome in aggressively treated meningeal carcinomatosis. Arch Neurol 1994;51:457-61.

91. Bokstein F, Lossos A, Siegal T. Leptomeningeal metastases from solid tumors: a comparison of two prospective series treated with and without intra-cerebrospinal fluid chemotherapy. Cancer 1998;82:1756-63.

92. Bokstein F, Lossos A, Siegal T. Leptomeningeal metastases (LM) in solid tumors: exclusion of intra-CSF chemotherapy does not affect treatment outcome. Comparison of two prospective series. Neurology 1997;48:1029.

93. Chamberlain MC, Kormanik P. Carcinoma meningitis secondary to non-small cell lung cancer: combined modality therapy. Arch Neurol 1998;55:506-12.

94. Oechsle K, Lange-Brock V, Kruell A, Bokemeyer C, de Wit M. Prognostic factors and treatment options in patients with leptomeningeal metastases of different primary tumors: a retrospective analysis. J Cancer Res Clin Oncol 2010;136:1729-35.

95. Maemondo M, Inoue A, Kobayashi K, Sugawara S, Oizumi S, Isobe H, Gemma A, Harada M, Yoshizawa H, Kinoshita I, Fujita Y, Okinaga S, Hirano H, Yoshimori K, Harada T, Ogura T, Ando M, Miyazawa H, Tanaka T, Saijo Y, Hagiwara K, Morita S, Nukiwa T. Gefitinib or chemotherapy for non-small-cell lung cancer with mutated EGFR. $N$ Engl J Med 2010;362:2380-8.

96. Lee DW, Shin DY, Kim JW, Keam B, Kim TM, Kim HJ, Kim DW, Wu HG, Paek SH, Kim YW, Heo DS, Kim DG, Lee SH. Additional prognostic role of EGFR activating mutations in lung adenocarcinoma patients with brain metastasis: integrating with lung specific GPA score. Lung Cancer 2014;86:363-8.

97. Liao BC, Lee JH, Lin CC, Chen YF, Chang CH, Ho CC, Shih JY, Yu CJ, Yang JC. Epidermal growth factor receptor tyrosine kinase inhibitors for non-small-cell lung cancer patients with leptomeningeal carcinomatosis. J Thorac Oncol 2015;10:1754-61.

98. Togashi Y, Masago K, Masuda S, Mizuno T, Fukudo M, Ikemi Y, Sakamori Y, Nagai H, Kim YH, Katsura T, Mishima M. Cerebrospinal fluid concentration of gefitinib and erlotinib in patients with non-small cell lung cancer. Cancer Chemother Pharmacol 2012;70:399-405.

99. Jackman DM, Cioffredi LA, Jacobs L, Sharmeen F, Morse LK, Lucca J, Plotkin SR, Marcoux PJ, Rabin MS, Lynch TJ, Johnson BE, Kesari S. A phase I trial of high dose gefitinib for patients with leptomeningeal metastases from non-small cell lung cancer. Oncotarget 2015;6:4527-36.

100. Lee E, Keam B, Kim DW, Kim TM, Lee SH, Chung DH, Heo DS. Erlotinib versus gefitinib for control of leptomeningeal carcinomatosis in non-small-cell lung cancer. $J$ Thorac Oncol 2013;8:1069-74.

101. Hoffknecht P, Tufman A, Wehler T, Pelzer T, Wiewrodt R, Schutz M, Serke M, Stohlmacher-Williams J, Marten A, Maria Huber R, Dickgreber NJ. Efficacy of the irreversible ErbB family blocker afatinib in epidermal growth factor receptor (EGFR) tyrosine kinase inhibitor (TKI)-pretreated non-small-cell lung cancer patients with brain metastases or leptomeningeal disease. J Thorac Oncol 2015;10:156-63.

102. Nanjo S, Ebi H, Arai S, Takeuchi S, Yamada T, Mochizuki S, Okada Y, Nakada M, Murakami T, Yano S. High efficacy of third generation EGFR inhibitor AZD9291 in a leptomeningeal carcinomatosis model with EGFR-mutant lung cancer cells. Oncotarget 2016;7:3847-56.

103. Solomon BJ, Mok T, Kim DW, Wu YL, Nakagawa K, Mekhail T, Felip E, Cappuzzo F, Paolini J, Usari T, Iyer S, Reisman A, Wilner $\mathrm{KD}$, Tursi J, Blackhall F. First-line crizotinib versus chemotherapy in ALK-positive lung cancer. N Engl J Med 2014;371:2167-77.

104. Gainor JF, Ou SH, Logan J, Borges LF, Shaw AT. The central nervous system as a sanctuary site in ALK-positive non-small-cell lung cancer. J Thorac Oncol 2013;8:1570-3.

105. Costa DB, Kobayashi S, Pandya SS, Yeo WL, Shen Z, Tan W, Wilner $\mathrm{KD}$. CSF concentration of the anaplastic lymphoma kinase inhibitor crizotinib. J Clin Oncol 2011;29:e443-5.

106. Shaw AT, Kim DW, Mehra R, Tan DS, Felip E, Chow LQ, Camidge DR, Vansteenkiste J, Sharma S, De Pas T, Riely GJ, Solomon BJ, Wolf J, Thomas M, Schuler M, Liu G, Santoro A, Lau YY, Goldwasser M, Boral AL, Engelman JA. Ceritinib in ALK-rearranged non-small-cell lung cancer. N Engl J Med 2014;370:1189-97. 
107. Ou SH, Sommers KR, Azada MC, Garon EB. Alectinib induces a durable (>15 months) complete response in an ALK-positive nonsmall cell lung cancer patient who progressed on crizotinib with diffuse leptomeningeal carcinomatosis. Oncologist 2015;20:224-6.

108. Gainor JF, Sherman CA, Willoughby K, Logan J, Kennedy E, Brastianos PK, Chi AS, Shaw AT. Alectinib salvages CNS relapses in ALK-positive lung cancer patients previously treated with crizotinib and ceritinib. J Thorac Oncol 2015;10:232-6.

109. Arrondeau J, Ammari S, Besse B, Soria JC. LDK378 compassionate use for treating carcinomatous meningitis in an ALK translocated nonsmall-cell lung cancer. J Thorac Oncol 2014;9:e62-3.

110. Pestalozzi BC, Brignoli S. Trastuzumab in CSF. J Clin Oncol 2000;18:2349-51.

111. Ferrario C, Davidson A, Bouganim N, Aloyz R, Panasci LC Intrathecal trastuzumab and thiotepa for leptomeningeal spread of breast cancer. Ann Oncol 2009;20:792-5.

112. Kordbacheh T, Law WY, Smith IE. Sanctuary site leptomeningeal metastases in HER-2 positive breast cancer: a review in the era of trastuzumab. Breast 2016;26:54-8.

113. Zagouri F, Sergentanis TN, Bartsch R, Berghoff AS, Chrysikos D, de Azambuja E, Dimopoulos MA, Preusser M. Intrathecal administration of trastuzumab for the treatment of meningeal carcinomatosis in HER2-positive metastatic breast cancer: a systematic review and pooled analysis. Breast Cancer Res Treat 2013;139:13-22.

114. Rusnak DW, Affleck K, Cockerill SG, Stubberfield C, Harris R, Page M, Smith KJ, Guntrip SB, Carter MC, Shaw RJ, Jowett A, Stables J, Topley P, Wood ER, Brignola PS, Kadwell SH, Reep BR, Mullin RJ, Alligood KJ, Keith BR, Crosby RM, Murray DM, Knight WB, Gilmer TM, Lackey K. The characterization of novel, dual ErbB-2/EGFR, tyrosine kinase inhibitors: potential therapy for cancer. Cancer Res 2001;61:7196-203.

115. Geyer CE, Forster J, Lindquist D, Chan S, Romieu CG, Pienkowski T, Jagiello-Gruszfeld A, Crown J, Chan A, Kaufman B, Skarlos D, Campone M, Davidson N, Berger M, Oliva C, Rubin SD, Stein S, Cameron D. Lapatinib plus capecitabine for HER2-positive advanced breast cancer. $N$ Engl J Med 2006;355:2733-43.
116. Coiffier B, Lepage E, Briere J, Herbrecht R, Tilly H, Bouabdallah R, Morel P, Van Den Neste E, Salles G, Gaulard P, Reyes F, Lederlin P, Gisselbrecht C. CHOP chemotherapy plus rituximab compared with CHOP alone in elderly patients with diffuse large-B-cell lymphoma. N Engl J Med 2002;346:235-42.

117. Rubenstein JL, Fridlyand J, Abrey L, Shen A, Karch J, Wang E, Issa S, Damon L, Prados M, McDermott M, O’Brien J, Haqq C, Shuman M. Phase I study of intraventricular administration of rituximab in patients with recurrent CNS and intraocular lymphoma. J Clin Oncol 2007;25:1350-6

118. Schulz H, Pels H, Schmidt-Wolf I, Zeelen U, Germing U, Engert A. Intraventricular treatment of relapsed central nervous system lymphoma with the anti-CD20 antibody rituximab. Haematologica 2004;89:753-4.

119. Floudas $\mathrm{CS}$, Chandra AB, Xu Y. Vemurafenib in leptomeningeal carcinomatosis from melanoma: a case report of near-complete response and prolonged survival. Melanoma Res 2016;26:312-5.

120. Krieg AM, Efler SM, Wittpoth M, Al Adhami MJ, Davis HL. Induction of systemic TH1-like innate immunity in normal volunteers following subcutaneous but not intravenous administration of CPG 7909, a synthetic B-class CpG oligodeoxynucleotide TLR9 agonist. $J$ Immunother 2004;27:460-71.

121. Ursu R, Taillibert S, Banissi C, Vicaut E, Bailon O, Le Rhun E, Guillamo JS, Psimaras D, Tibi A, Sacko A, Marantidou A, Belin C, Carpentier AF. Immunotherapy with CpG-ODN in neoplastic meningitis: a phase I trial. Cancer Sci 2015;106:1212-8.

122. Carpentier A, Laigle-Donadey F, Zohar S, Capelle L, Behin A, Tibi A, Martin-Duverneuil N, Sanson M, Lacomblez L, Taillibert S, Puybasset L, Van Effenterre R, Delattre JY, Carpentier AF. Phase 1 trial of a CpG oligodeoxynucleotide for patients with recurrent glioblastoma. Neuro Oncol 2006;8:60-6.

123. Carpentier A, Metellus P, Ursu R, Zohar S, Lafitte F, Barrie M, Meng Y, Richard M, Parizot C, Laigle-Donadey F, Gorochov G, Psimaras D, Sanson M, Tibi A, Chinot O, Carpentier AF. Intracerebral administration of $\mathrm{CpG}$ oligonucleotide for patients with recurrent glioblastoma: a phase II study. Neuro Oncol 2010;12:401-8. 